Esta obra forma parte del acervo de la Biblioteca Jurídica Virtual del Instituto de Investigaciones Jurídicas de la UNAM www.juridicas.unam.mx

\title{
LA TRANSICIÓN A LA DEMOCRACIA EN EL ESTADO DE MÉXICO DESDE UNA PERSPECTIVA JURÍDICO- ELECTORAL (1978-2012)
}

THE TRANSITION TO DEMOCRACY IN MEXICO STATE FROM A LEGAL ELECTORAL PERSPECTIVE (1978-2012)

FrancisCo LIZCANO FERNÁNDEZ

Felipe Carlos Betancourt Higareda

Hilda NAESSENS ${ }^{1}$

\section{Sumario:}

I. Introducción

II. Padrón electoral y lista nominal

III. Autonomía de las autoridades electorales

IV. Equidad financiera

V. Equidad en el acceso a los medios de comunicación

VI. Organización del proceso electoral

VII. Escrutinio y cómputo de los votos

VIII. Justicia electoral

IX. Conclusiones

RESUMEN: El presente artículo tiene como principal objetivo analizar la evolución de la normatividad jurídico-electoral en el Estado de México entre 1978 y 2012, la cual ha regulado las elecciones realizadas en esta entidad de la República Mexicana para

\footnotetext{
${ }^{1}$ Los tres autores son investigadores de la Universidad Autónoma del Estado de México (Facultad de Humanidades y Centro de Investigaciones en Ciencias Sociales y Humanidades) y agradecen a Ivonne Maya Espinoza y a Francisco Javier Duarte Jove su entusiasmo en la recopilación de la información para este texto.
} 
Esta obra forma parte del acervo de la Biblioteca Jurídica Virtual del Instituto de Investigaciones Jurídicas de la UNAM www.juridicas.unam.mx

DOI: http://dx.doi.org/10.22201/iij.24487910e_2016.9.10098

seleccionar a su gobernador, a los miembros de su Poder Legislativo y a sus ayuntamientos. A partir de tal análisis se demuestra que la promulgación del Código Electoral del Estado de México en 1996 expresa un cambio profundo en la democraticidad de la legislación electoral del Estado de México, pues establece normas que aseguran niveles de limpieza y equidad cualitativamente superiores a los indicados en la Ley de Organizaciones Políticas y Procesos Electorales del Estado de México, vigente entre 1978 y 1996.

Palabras clave: elecciones, legislación electoral, transición a la democracia, Estado de México.

ABSTRACT: This research paper has as its main purpose to compare diachronically the electoral law of Mexico State between 1978 and 2012, which has ruled the different elections of governor, members of the local congress and municipalities of this Mexican federal entity. From this analysis, we demonstrate that the enactment of the Electoral Code of Mexico State in 1996 expresses a profound change in the democratic quality of the electoral law of Mexico State, since it sets up norms that assure qualitatively superior levels of neatness and fairness than those achieved through the Act of Political Organizations and Electoral Procedures of Mexico State, which was enforced between 1978 and 1996.

Key words: elections, electoral law, transition to democracy, Mexico State.

\section{INTRODUCCIÓN}

El presente artículo tiene como principal objetivo analizar la transformación de la normatividad jurídico-electoral en el Estado de México entre 1978 y 2012 - la cual ha regulado las elecciones realizadas en esta entidad de la República mexicana para seleccionar a su gobernador, a los miembros de su Poder Legislativo y a sus ayuntamientos - para detectar sus cambios de democraticidad. A lo largo de este lapso, de más de 30 años, han estado vigentes dos cuerpos normativos en materia electoral en la mencionada entidad federativa (la más poblada del país): la Ley de Organizaciones y Procedimientos Políticos Electorales del Estado de México, en adelante (LOPPEEM), vigente entre 1978 y 1996, y el Código Electoral del Estado de México, en adelante (CEEM), promulgado en 1996 y vigente, con las reformas del caso, hasta la actualidad (mayo de 2012).

Para llevar a cabo este análisis, el presente trabajo se divide en siete apartados centrales que dan cuenta de las variables seleccionadas para demostrar la hipótesis que planteamos en este artículo: Padrón electoral y lista nominal, Autonomía de las autoridades electorales, Equidad financiera, Equidad en el acceso a los medios de 
Esta obra forma parte del acervo de la Biblioteca Jurídica Virtual del Instituto de Investigaciones Jurídicas de la UNAM www.juridicas.unam.mx

comunicación, Organización del proceso electoral, Escrutinio y cómputo de los votos y Justicia electoral. Variables que fueron elegidas a partir de dos criterios. Por un lado, permiten distinguir las elecciones democráticas de las que no lo son, pues se refieren a las dos cuestiones más importantes: la limpieza — que los resultados electorales se correspondan estrictamente con los votos emitidos legalmente por los electores - y la competencia equitativa entre las organizaciones que rivalizan en las elecciones. Por otro lado, hemos prescindido de variables relativas a principios, para concentrarnos en normas procedimentales concretas cuyo cumplimiento es más fácil de comprobar que el de aquéllos; sin embargo, no debe olvidarse que estas normas procedimentales son las que hacen posible la concreción de esos principios y que éstos, a su vez, están directamente vinculados con las dos características que hemos señalado como esenciales del acceso al poder democrático. En efecto, los principios electorales que el Código Federal de Instituciones y Procedimientos Electorales (Cofipe) proclama desde 1996, y que han sido retomados por la legislación mexiquense, desde entonces para guiar los procesos electorales son los de: objetividad de la información electoral, imparcialidad de los árbitros, apego a la legalidad de los involucrados, independencia de los organizadores y certidumbre de que todo el proceso se ajusta a las normas jurídicas vigentes. $^{2}$

Dos preguntas principales de investigación han guiado nuestro estudio: ¿en qué medida la normatividad jurídico-electoral estudiada se hizo más democrática entre 1978 y 2012 y, en caso afirmativo, ¿Cuáles fueron los hitos más importantes al respecto? La importancia de estas interrogantes radica, sobre todo, en que sus contestaciones - pese a su naturaleza exclusivamente jurídica- contribuyen a esclarecer cambios que no se circunscribieron al ámbito jurídico, sino que por el contrario, incidieron intensamente en la realidad política mexiquense, pues los cambios analizados en materia jurídicoelectoral condicionaron en alto grado el incremento de la democraticidad de los procesos electorales estatales, lo que a su vez constituye un factor fundamental para determinar si un régimen político, en este caso el del Estado de México, es en su

\footnotetext{
${ }^{2}$ Congreso de la Unión, Código Federal de Instituciones y Procedimientos Electorales, artículo 105, fracción II http://Www.diputados.gob.mx/LeyesBiblio/pdf/COFIPE.pdf, consultado el 27 de enero de 2012. En la doctrina jurídico-electoral mexicana se suele agregar a los principios mencionados el profesionalismo de las autoridades electorales.
} 
Esta obra forma parte del acervo de la Biblioteca Jurídica Virtual del Instituto de Investigaciones Jurídicas de la UNAM www.juridicas.unam. $m x$ conjunto, democrático o autoritario. ${ }^{3}$

Somos conscientes de que las prescripciones jurídicas relativas al régimen político (lo mismo podría decirse de otras materias jurídicas) no siempre se han correspondido ni en México ni en ningún otro país, con las características que en la realidad ha tenido el régimen político al que supuestamente regulaban. Por ejemplo, la independencia real de los poderes Legislativo y Judicial ante el Ejecutivo fue mucho menor que la prescrita constitucionalmente en muchos periodos de la historia de México como nación soberana. Sin embargo, existen disposiciones jurídicas en materia política que necesariamente trascienden en el ámbito jurídico, porque determinan (en el sentido estricto de esta palabra, que implica una relación de causalidad más fuerte que el verbo condicionar) la realidad correspondiente. Por ejemplo, el reconocimiento de los derechos políticos de las mujeres, en México como en cualquier país, ha determinado que existieran mujeres que, por lo menos, votaran en los procesos electorales más relevantes de una nación, en tanto que el no reconocimiento de tales derechos determina que las mujeres no puedan votar ni ser votadas en dichos procesos electorales. Por tanto, el análisis de los cambios jurídico-políticos a lo largo del tiempo cobra más relevancia cuando los cambios condicionan poderosamente (y con mayor razón cuando determinan) el funcionamiento del régimen político en el que se inscriben. Así sucede en el presente artículo, pues analiza cambios jurídico-electorales que se constituyeron en elementos fundamentales para que las elecciones mexiquenses pudieran considerarse democráticas, lo que, como se indicaba, es un factor necesario, aunque no suficiente para que un régimen político sea calificado como democrático.

Con relación a las preguntas de investigación mencionadas, la presente investigación pretende demostrar, en lo fundamental, que la promulgación del CEEM en 1996 expresó un cambio profundo en la democraticidad de la legislación electoral del Estado de México, pues estableció normas que aseguraron niveles de limpieza y equidad cualitativamente superiores a los propiciados por la LOPPEEM. Esta hipótesis cobra todo su sentido al avalar una suposición más abarcadora: las primeras elecciones locales en

\footnotetext{
${ }^{3}$ Actualmente, existe consenso entre los politólogos acerca de que una definición correcta de régimen político-democrático debe aludir al acceso al poder de sus principales a través de procesos limpios y competidos. La discusión al respecto se centra en la conveniencia, que nosotros compartimos, de añadir a la mencionada característica otras relativas al ejercicio del poder, como la tolerancia ante el disenso o la independencia de poderes.
} 
Esta obra forma parte del acervo de la Biblioteca Jurídica Virtual del Instituto de Investigaciones Jurídicas de la UNAM www.juridicas.unam. $m x$ https://biblio.juridicas.unam.mx/bjv

https://revistas.juridicas.unam.mx/

DOI: http://dx_doi_org/10.22201/iij_24487910e_2016.9.10098

esta entidad federativa bajo este nuevo código, celebradas también en 1996, constituyen el hito principal de su transición a la democracia; es decir, del paso de un sistema de partido hegemónico a otro de carácter democrático (pluripartidista y competitivo). De esta manera, la transición a la democracia en el Estado de México habría coincidido en el tiempo y habría sido del mismo tipo que la de la República mexicana. ${ }^{4}$

Después de emplear distintos tipos de búsqueda -como selección por título, lectura selectiva e incluso, cuando el número de textos era especialmente abundante, búsqueda por palabras clave- en las bases de datos que contienen tanto las tesis aprobadas durante los últimos quinquenios en las facultades de Derecho -unas $11 \mathrm{mil}$ de licenciatura y 318 de posgrado- ,y Ciencias Políticas y Sociales -986 de licenciatura y 168 de posgrado- de la Universidad Autónoma del Estado de México, así como los 420 textos publicados en la revista Apuntes Electorales del Instituto Electoral del Estado de México, en principio podemos afirmar que el tema jurídico-electoral no ha recibido la atención que su importancia amerita, por lo que mucho queda por analizar al respecto. ${ }^{5}$ Asimismo, encontramos que la mayoría de los trabajos que contienen análisis jurídicoelectorales de cierta extensión, a diferencia del presente artículo, son de carácter sincrónico y/o, pese a ser diacrónicos no analizan variables bien delimitadas. En uno de

${ }^{4}$ Respecto al ámbito federal, diversos autores han sostenido el papel decisivo desempeñado por las reformas jurídico-electorales en la transición a la democracia en la República mexicana, y en especial la de 1996. Mencionamos, a modo de ejemplo, algunas referencias: Ávila Ortiz, Raúl y Daniel Zovatto, “México: principio de equidad y nuevas reglas de la contienda electoral", en Córdova Vianello, Lorenzo y Salazar Ugarte, Pedro (coords.), Estudios sobre la reforma electoral de 2007, hacia un nuevo modelo, México, Tribunal Electoral del Poder Judicial de la Federación, 2009, pp. 611 y 612; Merino, Mauricio, "La reforma electoral y el nuevo régimen político", en Rodríguez Araujo, Octavio (coord.), México ¿Un nuevo régimen político?, México, Siglo XXI, 2009, p. 240; Nohlen, Dieter, "Instituciones y cultura política”, en Córdova Vianello, Lorenzo y Salazar Ugarte, Pedro (coords.), Constitución, democracia y elecciones: la reforma que viene, México, UNAM, 2007, p. 14; Woldenberg, José, Salazar, Pedro et al. (2000), La mecánica del cambio político en México. Elecciones, partidos y reformas, México, Cal y Arena, 2000, p. 427; Woldenberg, José, “Balance y perspectiva de la reforma electoral 2007", en Alcocer, Jorge y Córdova Vianello, Lorenzo (coords.), Democracia y reglas del juego, México, UNAM, 2010, p. 69; Woldenberg, José, Historia mínima de la transición democrática en México, México, El Colegio de México, 2012, pp. 13 y 116.

${ }^{5}$ Naessens, Hilda y Duarte Jove, Francisco Javier, llevaron a cabo estas búsquedas y procesaron la información correspondiente. 
Esta obra forma parte del acervo de la Biblioteca Jurídica Virtual del Instituto de Investigaciones Jurídicas de la UNAM www.juridicas.unam. $m x$ https://biblio.juridicas.unam.mx/bjv

https://revistas.juridicas.unam.mx/

DOI: http://dx_doi_org/10.22201/iij_24487910e_2016.9.10098

estos dos casos se encuentran siete artículos de Apuntes Electorales, ${ }^{6} 17$ tesis de licenciatura de la Facultad de Derecho ${ }^{7}$ y dos tesis de licenciatura de la Facultad de

${ }^{6}$ Arzuaga Magnoni, Javier y Gayet, Cecilia, “El avance de la pluralidad electoral en los sistemas políticos locales del Estado de México", Apuntes Electorales, Toluca, nueva época, año I, núm. 2, septiembrenoviembre de 2000, pp. 191-200; Cortés Padilla, Ricardo, “El proceso electoral 2009 en los municipios del Estado de México. El repunte de los triunfos priistas", Apuntes Electorales, Toluca, nueva época, año VIII, núm. 38, octubre-diciembre de 2009, pp. 113-136; Hernández Jácome, Ana Luisa, “El financiamiento público en el Estado de México", Apuntes Electorales, Toluca, primera época, año I, núm. 4, 1999, pp. 73-94; Juárez Franco, Miguel Ángel, “Experiencia en la organización, capacitación electoral y PREP en el Estado de México. Una alternativa", Apuntes Electorales, Toluca, nueva época, año I, núm. 12, abril-junio de 2003, pp. 212-225; Legorreta Martínez, Guillermo y Cedillo Victoria,Roberto, “La instauración del pluralismo moderado en el sistema de partidos del Estado de México, análisis de la actuación electoral de las fuerzas políticas del periodo 1996-2000", Apuntes Electorales, Toluca, nueva época, año I, núm. 7, enero-marzo de 2002, pp. 111226; Vázquez Ceballos, Cristo Avimael, “Competencia y competitividad electorales. Dos dimensiones explicativas de la transformación de los comicios municipales en el Estado de México", Apuntes Electorales, Toluca, nueva época, año VIII, núm. 35, enero-marzo de 2009, pp. 9-46; Vilchis Flores, Sandra Ivón, “La legalidad del voto a favor de los candidatos independientes en el proceso electoral del Estado de México", Apuntes Electorales, Toluca, primera época, núm. 4, diciembre de 1999, pp. 201-260.

${ }^{7}$ Aburto Hernández, Gustavo, La reforma electoral en México, 1969; Bernal Oceguera, Alma Patricia, Instauración de una normatividad efectiva para los procedimientos del Registro Federal de Electores, como medio para alcanzar la democracia, 2001; Ceballos Peña, Napoleón, Análisis jurídico al artículo 5 del Código Electoral del Estado de México, 2005; Domínguez Díaz, Verónica Elizabeth, Análisis al segundo párrafo del artículo 157 del Código Electoral del Estado de México, 2007; Elizalde Marcos, María Guadalupe, Análisis jurídico del sistema electoral federal y proyecto de reforma, 2002; Gonzales García, Gabriel, Propuesta de reforma al Código Electoral, para establecer la regulación de precampañas electorales en el Estado de México, 2004; Hernández Cardoso, Luis, El sistema jurídico electoral en México, su análisis a partir de 1988, 1996; Hernández Montesinos, Ricarda, Análisis jurídico normativo de los artículos 90., al 13 del Código Electoral del Estado de México, 2001; Laredo Chávez, Araceli, Análisis e interpretación jurídica del artículo 298 del Código Electoral del Estado de México, 2003; López López, Eleazar, Reforma electoral en materia de fiscalización de los recursos privados de los partidos políticos en México, 2005; Martínez Mejía, Josué, Análisis lógico jurídico del artículo 5o., del Código Electoral del Estado de México. El voto: derecho u obligación, 2008; Molina Ayala, Araceli, Análisis del artículo 50., constitucional respecto de los artículos 88, 114, 123 del Código Electoral del Estado de México, 2002; Monroy del Mazo, Angélica, El régimen jurídico de los partidos políticos en la reforma electoral de 1999 en el Estado de México, 2001; Noguez Labat, Sergio Sixto, La reforma electoral en el Estado de México y el Tribunal Estatal Electoral, 1991; Nonato Díaz, Irma Margarita, Análisis jurídico de las reformas al Código Electoral del Estado de México, respecto de la Ley de Organizaciones y Procesos Electorales, 1998; Osorio Alcalá, Juan Carlos, Inconstitucionalidad del artículo 313 del Código Electoral del Estado de México, 2007; Rendón Valencia, Martha Isela, Estudio comparativo en el marco político, electoral y jurídico de las elecciones federales del 2006 en la república mexicana y en el 
Esta obra forma parte del acervo de la Biblioteca Jurídica Virtual del Instituto de Investigaciones Jurídicas de la UNAM www.juridicas.unam. $m x$

DOI: http://dx.doi.org/10.22201/iij_24487910e_2016.9.10098

Ciencias Políticas y Sociales. ${ }^{8}$ De las tesis claramente dedicadas al análisis jurídicoelectoral de carácter sincrónico, dos tercios se refieren a cuestiones ocurridas en el siglo XXI, 22\% a los asuntos sucedidos en la última década de la centuria pasada y el resto ubica su objeto de estudio en los decenios de 1970 y 1980.

El mencionado proceso de búsqueda y selección permitió encontrar nueve textos cuatro tesis de licenciatura de la Facultad de Derecho, dos tesis de maestría de esta misma facultad, una tesis de licenciatura de la Facultad de Ciencias Políticas y Sociales, y dos artículos de Apuntes Electorales- parecidos al presente estudio en tanto que contenían análisis jurídico-electorales de carácter diacrónico y una cierta delimitación de las variables de estudio analizadas. ${ }^{9}$ Otra similitud entre estos textos y el nuestro es que en general, todos coincidimos en que la evolución normativa en materia electoral ha sido progresiva. Más allá de estas coincidencias generales, las semejanzas son escasas. No es frecuente la percepción, que constituye la base de nuestra hipótesis, de que tales mejoras jurídico-electorales formaron parte de un cambio de régimen político, y mucho

extranjero, 2009; Valencia Alonso, Gustavo, Análisis jurídico de la propaganda electoral de los partidos políticos en los procesos electorales del Estado de México, 2002.

${ }^{8}$ Aguilar Reyes, Hugo, El comportamiento electoral en Toluca, las elecciones de 1996 y 1997, 1999; Rangel Maruri, Hugo y Fuente Cuevas, Francisco de la, Participación electoral y competitividad electoral en el Estado de México: elecciones de ayuntamientos 2000, 2003.

${ }^{9}$ Cárdenas Álamo, David Adolfo, Estudio jurídico de la institución del Colegio Electoral en la legislatura del Estado de México (tesis de licenciatura de la Facultad de Derecho), UAEM, 1994; Chávez Alcántara, Claudio César, "La reforma electoral durante la LV Legislatura del Estado de México", Apuntes Electorales, nueva época, año V, núm. 21, julio-septiembre de 2005, pp. 115-128; Gómez Sánchez, Jorge, Controversias en materia de propaganda electoral en el Estado de México ¿Un conflicto de normas jurídicas o principios democráticos? (tesis de maestría de la Facultad de Derecho), UAEM, 2009; Guevara Rodríguez, Brenda, El impacto del sistema electoral en la conformación del sistema de partidos en el Estado de México, 1990-2000 (tesis de licenciatura de la Facultad de Ciencias Políticas y Sociales), UAEM, 2002; Hernández Alpizar, Emilio, Análisis jurídico de la reforma electoral del Estado (tesis de licenciatura de la Facultad de Derecho), UAEM, 1997; Marín Sánchez, Efraín, “Sistema electoral y representación de los partidos políticos en la integración de la LIV Legislatura del Estado de México", Apuntes Electorales, Toluca, nueva época, año IX, núm. 41, septiembre-diciembre de 2010, pp. 105-124; Nonato, Irma Margarita, Análisis jurídico de las reformas al Código Electoral del Estado de México respecto de la Ley de Organizaciones Políticas y Procesos Electorales del Estado de México (tesis de licenciatura de la Facultad de Derecho), UAEM, 1998; Olvera García, José Luis, Análisis al Código Penal para el Estado de México, en materia de delito contra el proceso electoral (tesis de maestría de la Facultad de Derecho), UAEM, 2005; Villanueva Tovar, Arturo, Reforma de los artículos 304 y 332 del Código Electoral del Estado de México (tesis de licenciatura de la Facultad de Derecho), UAEM, 1998. 
Esta obra forma parte del acervo de la Biblioteca Jurídica Virtual del Instituto de Investigaciones Jurídicas de la UNAM www.juridicas.unam.mx

DOI: http://dx_doï.org/10.22201/iij_24487910e_2016.9.10098

menos lo es que de ello resultara, -como nosotros pensamos- una democracia (sin duda de baja calidad en una serie de cuestiones, con respecto al estado de derecho, por poner un solo ejemplo, pero un régimen político que cumple, como indicamos, con las características esenciales de la democracia). De hecho, de estos nueve textos sólo el de Guevara argumenta dicha transición a partir de 1996, pero ella sostiene que consistió en el paso de un sistema de partido hegemónico, en lo que coincidimos plenamente, a un sistema de pluralismo "limitado", con lo que manifiesta que, en contra de nuestro parecer, la transición a la democracia del régimen político mexicano se quedó trunca. Otro texto que pudiera considerarse cercano al nuestro es el de Nonato, ya que considera tanto la LOPPEEM como el CEEM. Empero, no compara sistemáticamente ambos ordenamientos jurídicos, al dedicar su tesis a la descripción de asuntos como la elección a gobernador con base en las normas del recientemente promulgado CEEM o las funciones del Instituto Electoral del Estado de México y del Tribunal Electoral del Estado de México, también de nueva creación.

Estas diferencias no dejan de resultar lógicas, pues en realidad no se detectó ningún texto que, como el nuestro, tuviera como objetivo central el estudio de los distintos grados de democracia detectables en la legislación electoral mexiquense. Las conexiones que al respecto se hacen en las obras consultadas no se basan, como en el nuestro, en el análisis individualizado y detallado de un número reseñable de variables de estudio, mucho menos pretenden abarcar un arco temporal tan dilatado. En realidad, la revisión realizada evidenció la poca frecuencia con la que se estudian individual y detalladamente variables de estudio previamente seleccionadas para poder, posteriormente, relacionar adecuadamente los asuntos tratados y argumentar con solidez la hipótesis y las conclusiones.

No queremos terminar este bosquejo del estado de la cuestión sobre nuestro objeto de estudio, así como de las aportaciones de nuestro trabajo, sin referirnos a cuatro obras importantes que, pese a que lo enfrentan tangencialmente, constituyen elementos de consulta relevantes en materia jurídico-electoral. Dos contienen estudios comparativos sincrónicos de las legislaciones estatales de nuestro país. ${ }^{10}$ Las otras dos consisten

\footnotetext{
${ }^{10}$ Becerra, Ricardo, Galindo, Jesús et al. Así se vota en la República. Las legislaciones electorales en los estados: un análisis comparado, México, Instituto de Estudios para la Transición Democrática, 1996; Crespo, José Antonio, Votar en los estados: análisis comparado de las legis/aciones electorales estatales en México, México, Miguel Ángel Porrúa-Centro de Investigación y Docencia Económicas, 1996.
} 
Esta obra forma parte del acervo de la Biblioteca Jurídica Virtual del Instituto de Investigaciones Jurídicas de la UNAM www.juridicas.unam. $m x$

básicamente en la compilación y descripción de leyes electorales mexiquenses. ${ }^{11}$

\section{PADRÓN ELECTORAL Y LISTA NOMINAL}

Las principales transformaciones democráticas en relación con el padrón electoral y la lista nominal de electores se produjeron en 1996, si bien hubo un avance en 1990 al primer asunto y otro en 1992 respecto a la credencial de elector. Sin duda, tales cambios normativos, que describiremos más adelante, han contribuido a la limpieza y la equidad de los procesos electorales del Estado de México.

En principio, este padrón estaba regulado en el capítulo IX (artículos 114-119) y capítulo X (artículos 120-123) del título tercero (del proceso electoral) de la LOPPEEM. ${ }^{12}$ El capítulo IX trataba sobre la depuración del padrón electoral del Estado de México, tarea que realizaba el Registro Estatal de Electores de esta entidad. Esta depuración tenía por objeto desincorporar del padrón electoral a las personas que debían ser excluidas debido a circunstancias particulares que les imposibilitaban objetivamente el ejercicio de sus derechos político-electorales (por ejemplo, los fallecidos, los sentenciados, los inhabilitados por procesos judiciales, etcétera). De acuerdo con el análisis de las subsecuentes reformas al marco jurídico del padrón electoral del Estado de México, se puede observar que poco a poco fueron evolucionando las medidas de seguridad jurídica para garantizar su confiabilidad. Una reforma positiva en este sentido fue la aprobada el 22 de junio de 1990, la cual creó el Comité Técnico de Vigilancia del Registro Estatal de Electores, y permitió una mayor participación de los partidos de oposición en la integración, depuración y actualización del padrón electoral de esta entidad federativa.

Esta reforma constituye un importante antecedente de la reforma electoral federal de 1996, la cual alentó a su vez la constante observación y revisión del padrón electoral por parte de los partidos políticos mexicanos. Desde la entrada en vigencia de esta nueva legislación electoral, el Instituto Federal Electoral (IFE), a través del Registro Federal de

\footnotetext{
${ }^{11}$ Arreola, Álvaro, Legislación electoral en el Estado de México: siglos XIX, XX Y XXI, 3a. ed; Toluca, Instituto Electoral del Estado de México, 2003; Mendoza Velázquez, Enrique, La lid democrática. Reforma electoral 1917-2003, Toluca, Gobierno del Estado de México,Instituto de Estudios Legislativos del Estado de México, Colegio de Ciencias Políticas y Administración Pública del Estado de México, 2004.

${ }^{12}$ XLVI Legislatura del Estado de México, Ley de Organizaciones Políticas y Procesos Electorales del Estado de México (LOPPEEM), en Mendoza, E. (comp.), La lid democrática. Reforma electoral 1917-2003, Anexo D, Toluca, 2003, versión electrónica.
} 
Esta obra forma parte del acervo de la Biblioteca Jurídica Virtual del Instituto de Investigaciones Jurídicas de la UNAM www.juridicas.unam.mx

Electores, está encargado de la integración, depuración y actualización del padrón electoral de todo el país, incluyendo por supuesto el padrón electoral del Estado de México, basándose, para cumplir estas tareas, en los principios jurídico-rectores de certeza, objetividad, imparcialidad, legalidad, independencia y profesionalismo. No obstante, el Registro Estatal de Electores del Estado de México subsiste hasta la actualidad, pero depende totalmente de los datos que le proporciona el IFE.

Por otra parte, si bien puede argumentarse que la realidad electoral del Estado de México entre 1978 y 1996 era muy distinta de lo estipulado en la norma jurídica entonces vigente, la existencia de normas jurídicas que, al menos en semilla, contenían disposiciones que pretendían garantizar la confiabilidad del padrón electoral de la entidad, inspiraron el perfeccionamiento subsecuente de dichas normas jurídicas.

En este sentido, quizás una de las reformas más trascendentales al Código Federal de Instituciones y Procedimientos Electorales (Cofipe) para garantizar la limpieza de todos los procesos electorales del país, la constituyó la prescripción desde 1992, de las credenciales de elector con fotografía, las cuales permiten detectar más fácilmente en el padrón electoral nacional que un elector posea indebidamente más de una credencial o una credencial con datos falsos.

Los artículos 110, 111 y 112 de la LOPPEEM regulaban las listas nominales para cada sección electoral del Estado de México. Estos artículos establecían un principio de objetividad e imparcialidad en los procesos electorales de esta entidad, al estipular la exhibición pública de las listas nominales antes de la realización de las jornadas electorales, para que así los ciudadanos mexiquenses pudieran solicitar oportunamente su inclusión a estas listas e incluso pudieran impugnar cualquier resolución negativa sobre su respectiva inclusión (artículo 106).

Un problema en México y en el Estado de México en aquél entonces (y todavía en la actualidad) era que la inscripción al padrón electoral constituía principalmente una cuestión voluntaria (un derecho) de todo nacional mexicano mayor de 18 años, y no era una cuestión automática (una obligación) para el Estado mexicano llevarla a cabo a partir de la información oficial recopilada a través del registro civil. ${ }^{13}$ Lo anterior significaba que

\footnotetext{
${ }^{13}$ A diferencia de lo sucedido en México, en otros países latinoamericanos como Argentina, Brasil y Chile, el voto es obligatorio, en tanto que de forma automática los nacionales de esos países son registrados en el respectivo padrón electoral y contemplados en las respectivas listas nominales.
} 
Esta obra forma parte del acervo de la Biblioteca Jurídica Virtual del Instituto de Investigaciones Jurídicas de la UNAM www.juridicas.unam.mx

cuando un ciudadano mexiquense solicitaba su inscripción al padrón electoral de esta entidad, ésta dependía de una decisión discrecional de las autoridades electorales correspondientes. Para empeorar la situación, los medios de impugnación del ciudadano afectado para combatir dicha decisión no le aseguraban un resultado positivo, lo cual abría un espacio para la potencial realización de una jornada electoral con un padrón electoral y unas listas nominales significativamente "rasuradas", situación que también potencialmente afectaba la debida equidad, libertad y limpieza del respectivo proceso electoral mexiquense.

Desde 1996, los ciudadanos y los partidos políticos en el Estado de México como en la República mexicana, en general, tienen oportunidad de revisar las listas nominales del 15 de marzo al 14 de abril del año correspondiente al proceso electoral federal (artículo 195, fracciones I y II del Cofipe), que en el caso del Estado de México coincide con la renovación de sus ayuntamientos y su legislatura estatal, para denunciar oportunamente cualquier indebida omisión de las mismas. ${ }^{14}$ Además, los representantes de los partidos políticos pueden poseer, si así lo desean, una copia de la lista nominal de la casilla electoral que les corresponde vigilar durante la jornada electoral (artículo 175, fracción VII del (EEM), así como materiales auxiliares para el cumplimiento de sus funciones, para comprobar fácilmente que el desarrollo de esta jornada cumple con los principios rectores de certeza, objetividad, imparcialidad, independencia, legalidad y profesionalismo.

\section{AUTONOMÍA DE LAS AUTORIDADES ELECTORALES}

Respecto a la selección de los consejeros electorales y de los magistrados electorales, los cambios más importantes se produjeron en 1996, cuando, en ambos procesos, el Ejecutivo estatal dejó de tener la última palabra y se exigió un mayor nivel de consenso (mayoría calificada) entre los diputados locales para los nombramientos respectivos.

El artículo 58 de la LOPPEEM establecía que la Comisión Estatal Electoral estaría

\footnotetext{
${ }^{14}$ Sin embargo, el artículo 192 del COFIPE, actualmente vigente, concede acceso permanente a los partidos políticos a la base de datos del padrón electoral y de las listas nominales, y el artículo 194, fracción I, concede del 25 de marzo al 14 de abril de cada uno de los años anteriores a las elecciones federales, la oportunidad a los partidos políticos de revisar el padrón electoral y las listas nominales para realizar las observaciones correspondientes.
} 
Esta obra forma parte del acervo de la Biblioteca Jurídica Virtual del Instituto de Investigaciones Jurídicas de la UNAM www.juridicas.unam.mx

DOI: http://dx_doï.org/10_22201/iij_24487910e_2016.9.10098

integrada de la siguiente forma: dos comisionados nombrados por el Poder Ejecutivo estatal (el secretario general de Gobierno y el director de Gobernación), un comisionado nombrado por el Poder Legislativo estatal, los comisionados nombrados por cada partido político registrado a nivel estatal y un notario público, designado por esta Comisión, de entre los más antiguos de la Ciudad de Toluca. Todos estos comisionados gozaban de voz y voto en las deliberaciones internas de la Comisión.

En contraste, el artículo 86 del CEEM publicado en $1996^{15}$ estableció que los consejeros del Instituto Electoral del Estado de México serían electos a través del voto de las 2/3 partes de la legislatura estatal de entre las propuestas que presentaran sus fracciones legislativas. Aparte de lo anterior, desde la reforma electoral del 10 de septiembre de 2008 se estableció otro requisito obligatorio: la publicación de una convocatoria pública que otorgue mayor certidumbre jurídica a los plazos, formas y términos de la elección de estos consejeros electorales (el presidente y los otros seis consejeros).

Respecto al método de elección de los magistrados electorales estatales, la LOPPEEM de 1978 establecía que los magistrados del Tribunal de lo Contencioso Electoral del Estado de México serían nombrados por la legislatura estatal a propuesta del Ejecutivo estatal, siendo suficiente la aprobación por mayoría absoluta $(50 \%+1)$ de la mencionada legislatura. La reforma más trascendente para garantizar la imparcialidad de los magistrados electorales del Estado de México consiste en que, a partir de 1996, se exige mayoría calificada del Congreso de este estado para aprobar sus nombramientos, y en que el origen de las propuestas es el Consejo de la Judicatura del Tribunal Superior de Justicia de esta entidad. El primer requisito coadyuva a que las fuerzas políticas representadas en el Poder Legislativo tengan que buscar un consenso de mayor calidad para el nombramiento de estos magistrados electorales, lo que redunda en una mejor garantía de su desempeño imparcial, profesional y objetivo.

\section{EQUIDAD FINANCIERA}

Este apartado trata sobre dos cuestiones: financiamiento público a partidos políticos y fiscalización de los recursos de pre campañas y campañas electorales. En ambos casos, la transformación principal se produjo en 1996, pero respecto a la primera cuestión hubo

\footnotetext{
${ }^{15}$ LII Legislatura del Estado de México, Código Electoral del Estado de México (CEEM), en Mendoza, E. (comp.), La lid democrática. Reforma electoral 1917-2003, Anexo D, México, 2003, versión electrónica.
} 
Esta obra forma parte del acervo de la Biblioteca Jurídica Virtual del Instituto de Investigaciones Jurídicas de la UNAM www.juridicas.unam. $m x$ https://biblio.juridicas.unam.mx/bjv

https://revistas.juridicas.unam.mx/

DOI: http://dx.doi.org/10.22201/iij.24487910e.2016.9.10098

otro cambio, aunque de menor envergadura, en 1990 y respecto a la segunda tampoco deben olvidarse los cambios ocurridos en 1999, 2005 y 2008.

En relación con el financiamiento a los partidos políticos, antes de 1990 la ley no preveía financiamiento público alguno para los partidos, por lo que es probable que en la realidad sólo el partido hegemónico tuviera asegurado el acceso a recursos económicos suficientes para sus funciones partidarias. En un principio, el segundo párrafo del artículo 45 de la LOPPEEM estipulaba que era "prerrogativa de los partidos políticos contar con un mínimo de elementos para (sus) actividades encaminadas a la obtención del sufragio popular", y el tercer párrafo establecía que gozaban de "exención de impuestos y derechos estatales, y municipales, en aquellos bienes o actividades destinados al cumplimiento de las funciones propias del partido". Sin embargo, esta ley no definía ni operacionalizaba dicho "mínimo" ni establecía mecanismos públicos para financiar la actividad partidista. No obstante, desde el 22 de junio de 1990 la LOPPEEM concedió financiamiento público a los partidos políticos registrados en el Estado de México y lo reguló detalladamente. Con todo, en esta normatividad, el financiamiento privado de los partidos tenía prevalencia sobre su financiamiento público. ${ }^{16}$

Con la promulgación del CEEM en 1996 se privilegió el financiamiento público sobre el privado. El CEEM de 1996 estableció en su artículo 58, que el financiamiento público a los partidos se asignaría así: 30\% en forma paritaria a todos los partidos con registro y $70 \%$ en forma proporcional. Aunque, en 2009 se reformó dicho artículo para ordenar, en su fracción II, inciso a, numerales 1 y 2, que el financiamiento público a partidos políticos se distribuiría de la siguiente forma: 15\% paritaria y 85\% en forma proporcional directa de la votación válida efectiva de cada partido político, en la última elección de diputados locales por el principio de mayoría relativa. Esta reforma está vigente hasta el presente (2012).

Con relación a la fiscalización de los recursos de pre campañas y campañas electorales se puede afirmar que, pese a los notorios avances en este asunto (sobre todo

\footnotetext{
${ }^{16}$ De acuerdo con la reforma del 22 de junio de 1990, el financiamiento público se otorgaba en función de la significación y presencia político-electoral del partido respectivo (artículo 45 A). Un partido tenía derecho a recibir anualmente al menos 1,000 veces el salario mínimo vigente (artículo 45 B), pero su financiamiento en los años con campañas electorales sería al menos el doble del señalado en el artículo mencionado. La reforma al artículo 45 B, publicada el 4 de febrero de 1993, incrementó el financiamiento público de los partidos políticos a un mínimo de 2,500 veces el salario mínimo vigente en la capital del estado.
} 
Esta obra forma parte del acervo de la Biblioteca Jurídica Virtual del Instituto de Investigaciones Jurídicas de la UNAM www.juridicas.unam.mx

DOI: http://dx_doi_org/10.22201/ijj.24487910e_2016.9.10098

como se indicó, en 1996, pero también en 1999, 2005 y 2008), la legislación mexiquense todavía tiene cierta laxitud, como se demuestra por ejemplo, al no exigir la entrega de informes mensuales ni trimestrales.

La LOPPEEM no contenía una regulación expresa que fiscalizara con claridad el origen del financiamiento y gastos de los partidos políticos locales. Sin embargo, el artículo 38, fracción VII, contemplaba la posibilidad de que esta fiscalización fuera prescrita por otros ordenamientos jurídicos. En contraste, el CEEM, promulgado en 1996, estipulaba en su artículo 60, la obligación de los partidos políticos de presentar un informe anual que diera cuenta del origen y monto de los ingresos que recibían por cualquier modalidad de financiamiento, así como su empleo y aplicación.

En 1999, 2005 y 2008 se aprobaron reformas sustanciales en el asunto del que trata este apartado, los cuales permanecen vigentes hasta la fecha. Los artículos modificados comprenden del 51 al 61 del CEEM. ${ }^{17}$ En la actualidad, el artículo 61 de este código exige a los partidos la presentación de informes semestrales de avance del ejercicio, informes anuales de gastos ordinarios, informes de campaña e informes de precampaña. Este mismo artículo ordena la realización de revisiones precautorias y aleatorias a las finanzas de los partidos durante las campañas electorales y establece sanciones jurídicas serias por irregularidades en el manejo de los recursos por parte de los partidos políticos. Si se desprenden conductas sancionables conforme a derecho, el Consejo General del IEEM lo notificará al Tribunal Electoral del Estado de México (TEEM) para los efectos legales conducentes, que incluso podría incluir la cancelación de la constancia de mayoría sin perjuicio de la aplicación de otras sanciones o penas que conforme a derecho llegaran a proceder.

Con la finalidad de llevar a cabo una estricta regulación jurídica del financiamiento privado se reformaron los artículos 60 y, sobre todo, del 58. La fracción VI del artículo 58 reformado establece que el financiamiento de la militancia estará conformado por cuotas de afiliados, aportaciones de organizaciones sociales de los partidos, cuotas voluntarias y cuotas de candidatos para campañas políticas. También establece que el órgano responsable del manejo del financiamiento privado del partido respectivo deberá expedir recibos por cada cuota o aportación realizada, para así acreditar el monto

\footnotetext{
${ }^{17}$ LVII Legislatura del Estado de México, Código Electoral del Estado de México, 2011, consultado el 27 de enero de 2012, http://www.infosap.gob.mx/leyes_y_codigos.htm/
} 
Esta obra forma parte del acervo de la Biblioteca Jurídica Virtual del Instituto de Investigaciones Jurídicas de la UNAM www.juridicas.unam.mx

ingresado. Por otra parte, esta fracción también concede discrecionalidad a los partidos políticos para determinar montos mínimos y máximos, la periodicidad de las cuotas ordinarias y extraordinarias de sus afiliados, así como el límite de cuotas voluntarias y personales (de los candidatos) a las campañas electorales. Sin embargo, en el inciso " $b$ " de esta fracción encontramos establecido un límite al financiamiento proveniente de simpatizantes (no así de militantes) del partido respectivo, el cual no podrá exceder el $10 \%$ del tope de gastos de campaña para gobernador del Estado de México y la aportación individual de cada simpatizante no podrá exceder de $0.5 \%$ de dicho tope.

V.Equidad en el acceso a los medios de comunicación

En relación con el acceso de los partidos políticos a medios de comunicación locales, los cambios más importantes se produjeron en 1996 y 2008.

La LOPPEEM (1978) establecía en su artículo 45, párrafo I, que los partidos políticos gozaban de la prerrogativa de disponer de los medios adecuados para sus tareas editoriales. Sin embargo, esta ley no les concedía expresamente el derecho de acceder a los medios de comunicación social para promover su plataforma política.

En contraste, el CEEM (publicado en 1996) experimentó un avance sustancial en cuanto al acceso de los partidos políticos a los medios de comunicación masiva. Además de otorgarles el derecho al financiamiento público para las campañas electorales de gobernador, diputados locales y ayuntamiento (artículo 57 I), prescribió su facultad de contratar tiempos en radio y televisión para difundir mensajes orientados a la obtención del voto (artículo 65). Cada partido político adquirió el derecho de disponer 15 minutos semanales en las estaciones de radio y televisión del Gobierno del Estado y de 30 minutos durante el periodo de campaña electoral (artículo 66). La principal conexión entre el derecho al financiamiento público y el derecho al acceso a medios de comunicación, ambos concedidos por el CEEM de 1996, consistía en que los partidos podían perfectamente utilizar este financiamiento público para comprar espacios en los medios de comunicación impresos y electrónicos del Estado de México. Hasta 2008, el CEEM concedía a los partidos políticos el derecho de contratar espacios en los medios de comunicación masiva (radio y televisión) en forma independiente de la autoridad electoral, pudiendo utilizar al efecto el financiamiento público recibido.

La reforma constitucional de 2007 en materia electoral impactó decisivamente, como no podía ser de otra manera, en la legislación electoral del Estado de México. En 2008, el 
Esta obra forma parte del acervo de la Biblioteca Jurídica Virtual del Instituto de Investigaciones Jurídicas de la UNAM www.juridicas.unam. $m x$ https://biblio.juridicas.unam.mx/bjv

https://revistas.juridicas.unam.mx/

DOI: http://dx.doi.org/10.22201/iij_24487910e.2016.9.10098

artículo 63 del CEEM fue reformado sustancialmente para quedar en los siguientes términos: el IEEM y los partidos políticos en el Estado tendrán derecho al uso permanente de los medios de comunicación conforme a las normas establecidas en el apartado B, de la base III del artículo 41 de la Constitución Política de los Estados Unidos Mexicanos y el artículo 12 de la Constitución particular. El IFE será autoridad única para la administración de los tiempos que les correspondan en radio y televisión.

Para un mejor entendimiento de dicho artículo y de la normatividad que en este asunto rige en el Estado de México, conviene reproducir textualmente lo establecido en las Constituciones federal y estatal en los puntos citados del artículo 63. El inciso c) del apartado B, de la base III, del artículo 41 de la Constitución Política de los Estados Unidos Mexicanos ${ }^{18}$ establece que el IFE administrará los tiempos que correspondan al Estado en radio y televisión en las estaciones y canales de la entidad federativa de acuerdo a [sic] los criterios señalados en el apartado A de la misma base. Los criterios más importantes al respecto de este apartado son los siguientes:

a) A partir del inicio de las precampañas y hasta el día de la jornada electoral quedarán a disposición del Instituto Federal Electoral cuarenta y ocho minutos diarios, que serán distribuidos en dos y hasta tres minutos por cada hora de transmisión en cada estación de radio y canal de televisión, en el horario referido en el inciso d) de este apartado;

b) Durante sus precampañas, los partidos políticos dispondrán en conjunto de un minuto por cada hora de transmisión en cada estación de radio y canal de televisión; el tiempo restante se utilizará conforme a lo que determine la ley;

c) Durante las campañas electorales deberá destinarse para cubrir el derecho de los partidos políticos al menos el ochenta y cinco por ciento del tiempo total disponible a que se refiere el inciso a) de este apartado;

d) Las transmisiones en cada estación de radio y canal de televisión se distribuirán dentro del horario de programación comprendido entre las seis y las veinticuatro horas;

e) El tiempo establecido como derecho de los partidos políticos se distribuirá entre los mismos conforme a lo siguiente: el treinta por ciento en forma igualitaria y el setenta por

\footnotetext{
${ }^{18}$ Cámara de Diputados del H. Consejo de la Unión, Constitución Política de los Estados Unidos Mexicanos, México, UNAM, Instituto de Investigaciones Jurídicas, 2011, consultada el 27 de enero de 2012, http://www.juridicas.unam.mx/infjur/leg/legmexfe.htm
} 
Esta obra forma parte del acervo de la Biblioteca Jurídica Virtual del Instituto de Investigaciones Jurídicas de la UNAM www.juridicas.unam.mx https://biblio.juridicas.unam.mx/bjv

https://revistas.juridicas.unam.mx/

DOI: http://dx_doi.org/10.22201/iij_24487910e_2016.9.10098

ciento restante de acuerdo a los resultados de la elección para diputados federales inmediata anterior;

Por su parte, el artículo 12 (en un nuevo párrafo) de la Constitución Política del Estado Libre y Soberano de México ${ }^{19}$ tuvo que ser reformado para concordar con lo prescrito por la Constitución nacional y quedar en los siguientes términos:

Los partidos políticos podrán acceder a la radio y televisión, conforme a lo dispuesto por el Apartado B de la Base III del Artículo 41 de la Constitución Federal. Los partidos políticos en ningún momento podrán contratar o adquirir, por sí o por terceras personas (sic) tiempos en cualquier modalidad en radio y televisión.

Como podemos observar, existe una diferencia sustancial entre lo establecido en el CEEM de 1996 y lo ordenado en el CEEM vigente (2012). Una, los partidos políticos locales ya no pueden contratar por sí mismos espacios en los medios de comunicación electrónicos e impresos y dos, los criterios de distribución de estos espacios están establecidos en primer lugar en la Constitución federal y en segundo lugar en la Constitución estatal, por lo que la legislación electoral estatal tuvo que ser ajustada a lo que prescriben ambas Constituciones. En tercer lugar, el IFE es la única autoridad (por lo que se excluye automáticamente a las autoridades electorales estatales) para administrar los tiempos de los partidos políticos registrados en el Estado de México en la radio y televisión mexiquenses (o incluso nacionales). Estas reformas constitucionales y legales en la materia fueron aplicadas, tanto por el IFE como por el IEEM, en los pasados procesos electorales estatales de 2009 y 2011.

\section{ORGANIZACIÓN DEL PROCESO ELECTORAL}

Las precampañas no fueron reguladas sino hasta 2005, pero las campañas ya lo habían sido, con todo detalle, en 1996 (en 1990 se mencionaron estas últimas por primera vez pero no se normaron).

Las precampañas no fueron reguladas ni en la LOPPEEM ni en el CEEM de 1996. Su regulación comenzó con la reforma del CEEM del 11 de marzo de 2005. La realidad político electoral del Estado de México poco a poco evidenció situaciones problemáticas derivadas de las intensas competencias internas en los partidos políticos para ganar nominaciones, lo que al final obligó al Congreso del Estado de México a promulgar una

\footnotetext{
${ }^{19}$ LVII Legislatura del Estado de México, Constitución Política del Estado Libre y Soberano de México, 2012, consultada el 27 de enero de 2012, http://www.infosap.gob.mx/constitucion.htm/
} 
Esta obra forma parte del acervo de la Biblioteca Jurídica Virtual del Instituto de Investigaciones Jurídicas de la UNAM www.juridicas.unam.mx

DOI: http://dx_doi_org/10.22201/iij_24487910e_2016.9.10098

normatividad jurídica que otorgara mayor certidumbre jurídica a los procesos electorales internos de los partidos políticos. La adición de los artículos 144, inciso A a 144 inciso H regula de forma detallada diversos aspectos de las precampañas electorales, como los topes de gastos y la revisión del origen, monto y destino de los recursos que se emplean durante las mismas. Esta adición fortalece los principios jurídico-rectores (imparcialidad, objetividad, legalidad, certeza e independencia) del proceso electoral mexiquense en sus etapas de preparación y organización.

Al igual que las precampañas, las campañas electorales no estaban reguladas en la LOPPEEM (promulgada en 1978). El 22 de junio de 1990, por primera vez esta ley menciona expresamente a las campañas electorales como etapas de los procesos electorales estatales mas no hay un desarrollo normativo al respecto.

Las campañas electorales se regularon detalladamente desde la promulgación del CEEM de 1996, del artículo 152 al 162 del capítulo II (de las campañas electorales) del título segundo (actos preparatorios de la elección) del libro cuarto (del proceso electoral). Estos artículos continúan vigentes hasta la fecha. ${ }^{20}$ Quizá la falta de experiencia de elecciones competidas en esta entidad, como en el resto del país, provocó que no fuera sino hasta 1996 la necesidad de regulación de las campañas electorales en el Estado de México como parte fundamental de la etapa de organización de los procesos electorales estatales.

El artículo 152 de este Código define las campañas electorales así como los actos de campaña, y establece que estos últimos deberán propiciar la exposición, desarrollo y discusión ante el electorado de los programas y acciones fijados en los documentos básicos y/o la plataforma electoral del partido político respectivo. Por su parte, el artículo 153 reitera los límites constitucionales y legales de las reuniones públicas derivadas de los actos de campaña, y el artículo 154 ordena un uso equitativo de los locales públicos entre los partidos políticos para las campañas electorales.

El artículo 155 establece la obligación de los partidos políticos de informar a la autoridad pública sobre la realización de marchas o reuniones que pudieran interrumpir la vialidad pública. Por otra parte, el artículo 156 reitera los límites constitucionales y legales de la propaganda electoral, y los artículos 157 y 158 definen los lugares en los

\footnotetext{
${ }^{20}$ LVII Legislatura del Estado de México, Código Electoral del Estado de México (CEEM), 2011, consultado el 27 de enero de 2012, http://Www.infosap.gob.mx/leyes_y_codigos.htm/
} 
Esta obra forma parte del acervo de la Biblioteca Jurídica Virtual del Instituto de Investigaciones Jurídicas de la UNAM www.juridicas.unam.mx

DOI: http://dx.doi.org/10.22201/iij_24487910e_2016_9.10098

que se puede colocar ésta. El artículo 159 establece las fechas de inicio y de término de las campañas electorales, regula las fechas y plazos límites de publicación de encuestas de opinión, así como los requisitos y criterios científicos que éstas deben cumplir. Por último, los artículos 160, 161 y 162 se refieren a los topes de gastos de campaña y propaganda electoral, definiendo qué comprenden estos gastos, y los criterios que se utilizarán para establecer su tope.

Como se puede observar, a partir de 1996 existió una seria preocupación de garantizar la equidad de los procesos electorales del Estado de México, a través de una regulación detallada y estricta de las campañas electorales, y empezó una evolución jurídica positiva en este sentido. En resumen, esta equidad se intentó conseguir a través de la regulación de los alcances y límites de las libertades civiles, así como a través del establecimiento de criterios claros para los topes de gastos de las campañas electorales mexiquenses.

\section{ESCRUTINIO Y CÓMPUTO DE LOS VOTOS}

Desde la promulgación del CEEM en 1996 entraron en vigor importantes reformas en relación con varios aspectos del tema de este apartado: escrutinio y cómputo de los votos en las casillas electorales, clausura de la casilla y remisión del expediente, programa de resultados electorales preliminares y cómputo de los votos en los consejos municipales y distritales.

Si bien es cierto que ya desde 1978 se prescribían ciertos mecanismos y reglas para garantizar de cierta forma la imparcialidad y objetividad de este escrutinio y cómputo, tales como el cómputo y la inutilización de boletas sobrantes, la anulación de votos cuando no era posible discernir la voluntad del elector, así como la firma de los representantes de partido de las actas de escrutinio, y cómputo, no fue sino hasta la promulgación del CEEM de 1996 cuando se establecieron mecanismos eficaces para fortalecer la certeza, objetividad e imparcialidad de tal escrutinio y cómputo en la casilla electoral.

Efectivamente, el CEEM de 1996 prescribe procedimientos conducentes al efecto: los funcionarios de casilla deben contar, además de las boletas, los ciudadanos que votaron en la casilla de acuerdo a la lista nominal con fotografía de electores; los representantes de partidos, debidamente acreditados en la casilla, tienen la facultad de verificar el cómputo a través de copias de la respectiva lista nominal y de diversos materiales 
Esta obra forma parte del acervo de la Biblioteca Jurídica Virtual del Instituto de Investigaciones Jurídicas de la UNAM www.juridicas.unam.mx

DOI: http://dx_doi_org/10.22201/iij_24487910e_2016.9.10098

auxiliares; las boletas utilizadas para votar deben estar foliadas (artículo 185) y pueden estar firmadas por alguno de los representantes de casilla para asegurar su autenticidad al momento del escrutinio y cómputo; las boletas sobrantes deben inutilizarse con dos rayas diagonales, así como contarse y guardarse en un sobre distinto de aquél que contuviera los votos válidos y nulos de la casilla; por último, los representantes de partidos pueden firmar bajo protesta las actas de escrutinio y cómputo, pueden presentar escritos de protesta que deberán anexarse al expediente y paquete electoral respectivo, tienen derecho de recibir copias legibles de todas las actas que se levanten durante la jornada electoral, de firmar los expedientes y paquetes electorales, y de acompañar al presidente de la casilla a entregarlos, si así lo desean.

Otra reforma que reforzó la certeza, imparcialidad y objetividad del escrutinio y cómputo de los votos consistió en que al exterior de la casilla, una vez terminado el escrutinio y cómputo de los votos, se deben pegar avisos con los resultados de la jornada electoral, los cuales pueden ser firmados bajo protesta por los representantes de los partidos políticos (artículo 239). Para terminar este listado de reformas, desde el CEEM promulgado en 1996, la nueva acta de escrutinio y cómputo refuerza también estos principios, ya que tiene apartados que deben llenarse con información que al final debe coincidir (número de votos válidos, número de votos nulos, número de boletas sobrantes e inutilizadas), y también debe indicar por escrito las relaciones de escritos de protesta e incidentes suscitados durante la realización del escrutinio y cómputo. Toda esta información servirá en el momento oportuno a la autoridad electoral tanto administrativa como judicial, para calificar la validez del escrutinio y cómputo realizado en la respectiva casilla electoral.

Si bien, ya desde 1978 el artículo 164 de la LOPPEEM facultaba a los representantes de partido para exigir garantías necesarias para la seguridad de los documentos y paquetes electorales una vez concluidas las labores de casilla, es a partir de 1996 cuando el CEEM regula de forma más detallada la clausura de la casilla y la remisión del expediente electoral respectivo, y pretende una entrega-recepción objetiva, imparcial, legal y cierta de los expedientes y paquetes electorales a los consejos distritales y municipales electorales, para así impedir, hasta el último momento de la jornada electoral, la falsificación de los resultados electorales en la casilla electoral respectiva. En efecto, el capítulo IV del título tercero, del libro cuarto (del proceso electoral) del CEEM (artículos 240-245) reglamenta específicamente esta etapa de la jornada electoral, a diferencia de 
Esta obra forma parte del acervo de la Biblioteca Jurídica Virtual del Instituto de Investigaciones Jurídicas de la UNAM www.juridicas.unam.mx

la LOPPEEM que no contenía ningún capítulo específico para regularla. Cabe mencionar que en esta actividad los representantes de casilla tienen un papel relevante para garantizar la entrega-recepción en los términos mencionados.

El Programa de Resultados Electorales Preliminares, en adelante PREP, constituye, desde 1996, otra reforma trascendente para garantizar la objetividad, imparcialidad, certeza e independencia del escrutinio y cómputo de los votos al término de la jornada electoral estatal. La LOPPEEM no contemplaba este programa en su normatividad pero a partir de 1996 el PREP se regula en el capítulo segundo, del título cuarto, del libro tercero del CEEM, en los artículos 251 y 252 (vigentes) y también en el artículo 102, fracción XX (también vigente). Este último señala que es atribución del secretario ejecutivo general del IEEM "establecer un mecanismo para la difusión inmediata en el Consejo General, de los resultados preliminares de las elecciones de gobernador del estado o de diputados". El artículo 251 establece el procedimiento para la captura y difusión del PREP, el cual resumimos en los siguientes términos: a) se reciben los paquetes electorales; b) se desprenden las copias de las actas de escrutinio y cómputo de los paquetes electorales, y se da lectura en voz alta de sus resultados, y c) la autoridad electoral realiza la suma correspondiente en la forma destinada al efecto, conforme al orden numérico de las casillas, para anotarse después en el lugar adecuado. Cabe mencionar que para garantizar el cumplimiento de los principios rectores (objetividad, imparcialidad, legalidad, certeza, independencia y profesionalismo) del proceso electoral mexiquense, el proceso de captura y difusión del PREP es monitoreado por los representantes de los partidos ante los consejos distritales y municipales del Estado de México.

Si bien, ya desde la LOPPEEM de 1978 se ordenaba el examen de los paquetes electorales y la realización de cómputos distritales y municipales de los votos (artículos 170 y 183), estas operaciones sólo podían realizarse hasta el domingo siguiente al de la jornada electoral. En contraste, el CEEM desde 1996 acortó el plazo para la realización de estas operaciones (artículos 254 y 270), ubicándolo en el miércoles posterior a la jornada electoral, lo que contribuyó a la certeza, imparcialidad y objetividad del escrutinio y cómputo de los votos, al impedir en una forma más realista y práctica la posible falsificación de los resultados contenidos en los paquetes electorales, si permanecían mucho tiempo expuestos a su posible alteración. Además, durante la realización de estos cómputos en los consejos distritales y municipales del Estado de México, el CEEM fortaleció el papel de los representantes de partidos políticos para corroborar la certeza, 
Esta obra forma parte del acervo de la Biblioteca Jurídica Virtual del Instituto de Investigaciones Jurídicas de la UNAM www.juridicas.unam.mx

DOI: http://dx_doi_org/10.22201/iij_24487910e_2016.9.10098 imparcialidad y objetividad de dichos cómputos.

\section{JUSTICIA ELECTORAL}

En los tres temas tratados en este apartado, la promulgación del CEEM en 1996 implicó avances importantes respecto a la imparcialidad de las instituciones electorales y a la regulación exhaustiva de la justicia electoral, lo que ha contribuido a fortalecer la democraticidad del entramado jurídico-electoral estudiado, si bien la LOPPEEM contenía al respecto semillas nada desdeñables, una reforma de 2008 ha mejorado lo relativo a las nulidades del proceso electoral previstas en 1996.

El mero recuento de las partes que los dos conjuntos normativos dedican a la justicia electoral evidencia el mayor interés que en esta materia tuvo el CEEM en comparación con la LOPPEEM. Por un lado, este avance se manifestó en que casi se duplicaron los artículos correspondientes. Por otro lado, mientras que en la LOPPEEM la justicia electoral era regulada en los cuatro capítulos del título sexto (del artículo 195 al 228), los cuales trataban sobre las nulidades, las sanciones, los recursos y el Tribunal de lo Contencioso Electoral de la entidad, en el CEEM de 1996 la justicia electoral se reguló en el libro sexto (en sus tres títulos y sus respectivos capítulos), del artículo 298 al 361.

En la actualidad, la justicia electoral también está regulada en el libro sexto del CEEM (con tres títulos y 16 capítulos), del artículo 297 al 360, pero el título segundo de este libro contiene tres capítulos más de los que poseía en 1996. El título primero del libro sexto del CEEM actual comprende las nulidades e incluye un capítulo único al efecto. El título segundo de este libro trata sobre los distintos medios de impugnación electoral en el Estado de México y está dividido en 14 capítulos que norman la competencia, la legitimación y la personería, los plazos y términos, las reglas para el trámite y sustanciación de los medios de impugnación, la improcedencia y el sobreseimiento, las notificaciones, la acumulación de juicios, los impedimentos, excusas y recusaciones, las pruebas, las resoluciones, los medios de apremio y correcciones disciplinarias, y los procedimientos especiales. El tercer y último título de este libro engloba sólo un capítulo que versa acerca de las infracciones y sanciones administrativas en materia electoral.

\section{Calificación de las elecciones}

Una de las omisiones regulativas de la LOPPEEM respecto a las etapas del proceso electoral, se refería a la calificación de las elecciones de gobernador y las del Congreso del Estado de México, pues, en realidad sólo normaba la calificación de las elecciones de 
Esta obra forma parte del acervo de la Biblioteca Jurídica Virtual del Instituto de Investigaciones Jurídicas de la UNAM www.juridicas.unam.mx

ayuntamientos. En aquél entonces, las elecciones de la legislatura y de la gubernatura del Estado eran calificadas, en la práctica, por la legislatura local que se convertía en Colegio Electoral para tal efecto, y las elecciones para renovar ayuntamientos eran calificadas en primera instancia por la Comisión Municipal Electoral y en la segunda instancia por la Comisión Estatal Electoral.

En contraste, en el CEEM, desde 1996, la calificación de las elecciones a gobernador del estado la realiza el Consejo General del IEEM (artículos 280 y 281), las elecciones de diputados locales son calificadas por los consejos distritales electorales (artículos 253258), y las elecciones de los miembros de los ayuntamientos son calificadas por los consejos municipales electorales (artículo 270). Todas estas elecciones locales son calificadas en segunda instancia y en forma definitiva e inatacable por el TEEM.

\section{Nulidades del proceso electoral}

El artículo 195 de la LOPPEEM establecía las causales de nulidad de la votación en casillas y su artículo 196 las causales de nulidad de las elecciones locales del Estado de México. Para ambos casos, podemos afirmar que si bien estas causales no estaban muy detalladas, como sí lo han estado en el CEEM desde 1996, constituían una semilla correcta para la respectiva declaración de nulidad. Ya desde la LOPPEEM el concepto determinante era crucial para poder anular bien la votación de una casilla o bien de una elección local. Sin embargo, las nulidades de elección o de votación en una o varias casillas sólo podían ser declaradas por el Colegio Electoral de la Legislatura del Estado o por la Comisión Estatal Electoral, dependiendo del tipo de elección local que se impugnara.

En contraste, en el CEEM, desde 1996, el TEEM se volvió la única autoridad que puede declarar tanto la nulidad de la votación en una o varias casillas como la nulidad de una elección local. Por otra parte, las causales de nulidad de la votación en una o varias casillas o de toda una elección local, han adquirido mayor precisión desde la promulgación del CEEM. Para que una causal sea procedente en la anulación de la respectiva votación y/o elección local, ésta debe ser "determinante" en los respectivos resultados electorales: se necesitan "violaciones sustanciales en forma generalizada, debidamente probadas, y que sean determinantes para el resultado de la elección" (artículo 300 del CEEM de 1996) para que la respectiva anulación proceda.

El 10 de septiembre de 2008 se promulgaron reformas al capítulo del CEEM sobre las 
Esta obra forma parte del acervo de la Biblioteca Jurídica Virtual del Instituto de Investigaciones Jurídicas de la UNAM www.juridicas.unam.mx

DOI: http://dx_doi_org/10.22201/iij_24487910e_2016.9.10098

nulidades y se adicionaron nuevas causales de anulación de votación o de elección, que son muy pertinentes en el contexto actual del Estado de México, como por ejemplo, manejar recursos provenientes de actividades ilícitas en forma determinante para el resultado de la elección; exceder los topes de gastos de campaña de manera determinante para el resultado de la elección, y utilizar recursos públicos o los destinados a programas sociales, de cualquier nivel de gobierno, en forma determinante para el resultado de la elección. Sin duda, estas reformas reflejan un perfeccionamiento de la normatividad jurídico-electoral en relación con las causales de nulidad de la votación tanto en una o varias casillas como en toda una elección local.

\section{Medios de impugnación legales}

de los resultados electorales

Podemos observar una transformación jurídica positiva en el Estado de México respecto a los medios de impugnación en materia electoral desde 1978. Para empezar, el capítulo segundo del título sexto de la LOPPEEM establecía los recursos que podían interponerse contra las resoluciones de los organismos electorales estatales: protesta, inconformidad, queja y revocación. La protesta se presentaba en contra de actos de escrutinio y cómputo en las casillas electorales, la queja para hacer valer las causales de nulidad en el acta de cómputo distrital, la inconformidad se presentaba contra actos del Registro Estatal de Electores, y la revocación en contra de los acuerdos de la Comisión Estatal Electoral. Sin embargo, aparte de estos medios de impugnación, el artículo 216 de la LOPPEEM contemplaba otros dos más: la revisión y la apelación, los cuales conocía el Tribunal Estatal de lo Contencioso Electoral, en adelante TECE. En total, el TECE conocía de tres tipos de medios de impugnación: apelación, queja y revisión; sin embargo, sus resoluciones a estos medios de impugnación podían ser modificadas por la legislatura y la Comisión Estatal Electoral del Estado de México (artículo 216). Lo anterior indicaba la falta de independencia de este tribunal y la subordinación de sus resoluciones a posteriores decisiones políticas.

Por su parte, el CEEM ha regulado desde 1996, en el título segundo de su sexto libro, medios de impugnación electoral semejantes a los señalados antes: revocación, apelación, revisión, escritos de protesta y recursos de inconformidad. A través de la revocación, los partidos políticos, candidatos y ciudadanos pueden solicitar la modificación de decisiones, resoluciones y dictámenes de las autoridades electorales. Mediante el recurso de revisión, los partidos políticos, candidatos y ciudadanos pueden 
Esta obra forma parte del acervo de la Biblioteca Jurídica Virtual del Instituto de Investigaciones Jurídicas de la UNAM www.juridicas.unam.mx https://biblio.juridicas.unam.mx/bjv

https://revistas.juridicas.unam.mx/

DOI: http://dx_doi_org/10.22201/iij_24487910e_2016.9.10098

solicitar que el Consejo General (CG) del IEEM resuelva en segunda instancia cualquier resolución de los consejos electorales distritales o municipales del Estado de México. Con el recurso de apelación, los partidos políticos pueden atacar resoluciones del CG del IEEM ante el TEEM, y los escritos de protesta, los representantes de casilla de los partidos políticos pueden hacer constar la presunta existencia de violaciones a la normatividad electoral durante la jornada electoral. Por último, a través del recurso de inconformidad, los partidos políticos y los candidatos pueden hacer valer las causales de nulidad de la votación en casillas y/o de la elección en un distrito o municipio concreto ante el TEEM.

El CEEM, desde 1996, no se limitó a establecer los medios de impugnación en materia electoral y los casos en que procedían sino que también reguló en forma detallada muchos aspectos de su presentación y substanciación; por ejemplo, los plazos y términos de su presentación, las reglas de procedimiento para la tramitación de estos recursos, los casos de improcedencia y sobreseimiento, la acumulación de los recursos, las pruebas admisibles, las resoluciones a los recursos, la formación de jurisprudencia y, por último, los efectos de estos recursos, especialmente los efectos del recurso de inconformidad. Podemos afirmar que toda esta regulación detallada significó el surgimiento de un auténtico derecho procesal electoral en el Estado de México.

\section{CONCLUSIONES}

En todos los aspectos analizados respecto a la legislación electoral —padrón electoral y lista nominal, autonomía de las autoridades electorales, equidad financiera, equidad en el acceso a los medios de comunicación, organización del proceso electoral, escrutinio y cómputo de los votos, y justicia electoral- se comprueba que la promulgación del CEEM en 1996 constituyó, sin la menor duda, la transformación más importante en todo el lapso estudiado (1978-2012) en relación con la democraticidad de la mencionada legislación. Por tanto, este lapso de más de 30 años debe dividirse en dos periodos separados por ese hito: 1978-1996 y 1996-2012. Sin embargo, ambos periodos admiten una subdivisión en su seno. El periodo (1978-1996), que corresponde con el tramo final del régimen político de partido hegemónico que imperó en México entre 1929 y 1996, puede subdividirse en dos etapas, en virtud de que en 1990 se produjeron avances importantes, aunque nunca de la profundidad de los ocurridos en 1996, en los siguientes asuntos: padrón electoral, financiamiento público a los partidos políticos y regulación de las campañas electorales. Por su parte, el periodo (1996-2012) que se corresponde con el régimen político democrático más prolongado y profundo de la historia mexicana, puede 
Esta obra forma parte del acervo de la Biblioteca Jurídica Virtual del Instituto de Investigaciones Jurídicas de la UNAM www.juridicas.unam.mx

DOI: http://dx_doi_org/10.22201/iij_24487910e_2016.9.10098

subdividirse en otras dos etapas, debido a los cambios que se produjeron en 2008 respecto al acceso de los partidos políticos a los medios de comunicación, la fiscalización de recursos de campaña y precampaña electorales, y la justicia electoral. ${ }^{21}$

En el primer periodo (1978-1996) existían lo que podríamos denominar semillas democráticas en materia jurídico-electoral, pues sólo fructificaron plenamente en el periodo siguiente. Aunque relevantes en sí mismos, estos elementos democráticos no eran suficientes para garantizar elecciones limpias y equitativamente competidas, debido a las omisiones legales señaladas en este trabajo, pero sobre todo a las prácticas políticas no democráticas que caracterizaron los procesos electorales en el régimen político de partido hegemónico, cuyo análisis se reserva para otra investigación al quedar fuera de la delimitación del objeto de estudio realizada para la presente.

En el segundo periodo (1996-2012), la normatividad jurídico-electoral -inspirada en los principios rectores de certeza, imparcialidad, objetividad, independencia, legalidad y profesionalismo- reguló en forma más detallada, estricta y democrática las distintas etapas del proceso electoral mexiquense. La mencionada promulgación del CEEM en 1996 es, precisamente, el principal hito jurídico en materia electoral en la transición a la democracia del Estado de México, pues se constituyó en un factor clave en el cambio de régimen político. Las normas publicadas en este cuerpo jurídico hicieron casi imposible el fraude electoral, al menos en un asunto tan medular como el escrutinio y cómputo de los votos. Asimismo, establecieron una situación de equidad básica entre los partidos políticos que compiten en las elecciones, la cual se ha fortalecido con las reformas ulteriores de 1998-1999 y 2008, que garantizan en mayor medida la competencia equitativa entre los partidos políticos, al controlar más estrictamente el acceso de los partidos políticos a los medios de comunicación, al regular más detalladamente la fiscalización de los recursos de los partidos políticos y los candidatos durante las precampañas y las campañas electorales, y al adicionar causales relevantes de anulación de la votación.

\footnotetext{
${ }^{21}$ Las reformas de 1998-1999, relativas principalmente a las variables de calificación de elecciones y justicia electoral, no nos parecieron lo suficientemente significativas para establecer las etapas correspondientes.
} 